\title{
Julius Elster and Hans Geitel - Dioscuri of physics and pioneer investigators in atmospheric electricity
}

\author{
Rudolf G. A. Fricke and Kristian Schlegel \\ Wolfenbüttel, Germany \\ Correspondence to: Kristian Schlegel (kristian.schlegel@copernicus.org)
}

Received: 11 November 2016 - Revised: 8 December 2016 - Accepted: 12 December 2016 - Published: 4 January 2017

\begin{abstract}
Julius Elster and Hans Geitel contributed to the physics at the turn of the 19-20th century in many ways. We first summarize the life of these exceptional scientists. Then - owing to the topic of this journal we focus on their atmospheric electricity research. With their experiments, careful evaluations and ingenious interpretation, Elster and Geitel made important contributions to precipitation electricity, the influence of solar radiation on the electric state of the atmosphere, the nature of charge carriers and the ionization of air by radioactivity. They proved their experimental skills by inventing new instruments with unprecedented accuracy and reliability. A very modern concept was their attitude to undertake long-term measurements at various locations. A section on their recognition in the physics community and their scientific distinctions concludes the paper.
\end{abstract}

\section{Brief biographies}

Julius Johann Philipp Ludwig Elster was born on 24 December 1854 in Blankenburg, Germany. His father had studied theology and obtained a doctorate degree at the University of Göttingen but worked as a private teacher. He was married to his niece, Clara Stegmann (1834-1894).

Hans Friedrich Karl Geitel, born on 16 June 1855 in Braunschweig, Germany, was the son of the forest superintendent Carl Geitel (1819-1875). When Hans was 6 years old his father received an appointment as head of the forest department in Blankenburg. This little town in the Harz was one of the residences of the dukes of Braunschweig-Lüneburg with a castle from the early 18 th century.

The Elster and the Geitel families were neighbours in Blankenburg. Being only 6 months apart in age, Julius and Hans were classmates throughout their entire school life. This companionship set the basis for a life-long friendship. They were both strongly interested in natural sciences, such as physics, chemistry and biology, starting experiments and research together, beyond their school education. They were quite up to date with contemporary scientific developments, experimenting with spectral analysis and electrical phenomena. In spring 1875 they both graduated with Abitur (final high school examinations), entitling them to enter university.
They started their university education in physics and mathematics at the University of Heidelberg. One of their teachers who particularly stimulated Elster's and Geitel's studies was the well-known Professor Georg Quincke (18341924). With him they kept a relationship even after their university years, frequently asking for his view and advice during their later research. After their third semester they transferred to the University of Berlin in order to learn from the famous physicists Gustav Kirchhoff (1824-1887) and Hermann von Helmholtz (1821-1894), as well as the mathematician Karl Weierstraß (1815-1897).

After the end of their university education in 1878, Elster and Geitel went their separate ways for a few years. Elster returned to Heidelberg and earned a $\mathrm{PhD}$ under supervision of his adored teacher Quincke; Geitel moved to Braunschweig, where his mother lived, and applied for a high school teaching position. After passing the state examination he was qualified to lecture in mathematics, physics and chemistry at Realschulen and Gymnasien (types of secondary schools). After his first teaching position at Gymnasium Martino-Katharineum in Braunschweig, Geitel was transferred to Gymnasium Große Schule (Grand School) in Wolfenbüttel on 1 October 1879. Wolfenbüttel, at that time a town of about 10000 inhabitants, located about $12 \mathrm{~km}$ south 
of Braunschweig, was the main residence of the dukes of Braunschweig-Wolfenbüttel until 1753.

After finishing his doctorate in Heidelberg, Elster strived for a teaching position as well. By lucky circumstances and advocacy of his friend Geitel he also obtained a position at the Große Schule in Wolfenbüttel in April 1881. The two friends were united again!

Elster and Geitel remained Gymnasium teachers in Wolfenbüttel for their whole lives, despite the fact that university positions were offered to them (see Sect. 3). They both were talented and dedicated teachers indeed. They had a gift for inspiring their students to pursue a certain subject and were well respected. Almost affectionately they were nicknamed "Jule" (Elster, short for Julius) and "Itsche" (Geitel, meaning "frog", because he had a great collection of frogs). The Primaner (students in their last year of Gymnasium) were invited to private parties with Elster and Geitel; these invitations were highly esteemed. The supervisory school authority honoured their engagement with the titles Oberlehrer (senior teacher) in 1889/1990 and Gymnasialprofessor (professor at Gymnasium) in 1896.

Elster married the daughter of a bank owner on 15 April 1886, but Geitel remained a bachelor until 1922, when he married a cousin (after Elster's death). The Elsters, being financially well off, could afford to build a spacious house twice in their life. These houses and the garden provided enough space for the extensive experiments of both friends (Fig. 1).

Fricke (1992) concluded from the study of the inheritance letters and notes (edited by Kröger, 1981) that Elster was a gifted and brilliant experimenter, whereas Geitel was the "thinker" and theorist of the two. Thus they represented an ideal combination of scientists.

Julius Elster died on 8 April 1920 during a health treatment in Bad Harzburg and was buried in the cemetery of Wolfenbüttel. Hans Geitel outlived his friend by three years. He died on 23 August 1923 in Wolfenbüttel and was buried there as well.

\section{Scientific research and achievements}

Elster's and Geitel's scientific interests were vast. Their investigations included electric phenomena in gases and liquids, experimental techniques and instruments, material sciences, meteorology, photoelectricity, photometry, and radioactivity. Their main interest, however, was atmospheric electricity. This field was something like a leitmotif in their research; several of the other topics can be regarded as supplementary investigations. Their steps in atmospheric electricity research were based logically on each other, from the measurements of electric quantities of the atmosphere to their nature, their behaviour and their origin, as will be described in the following.

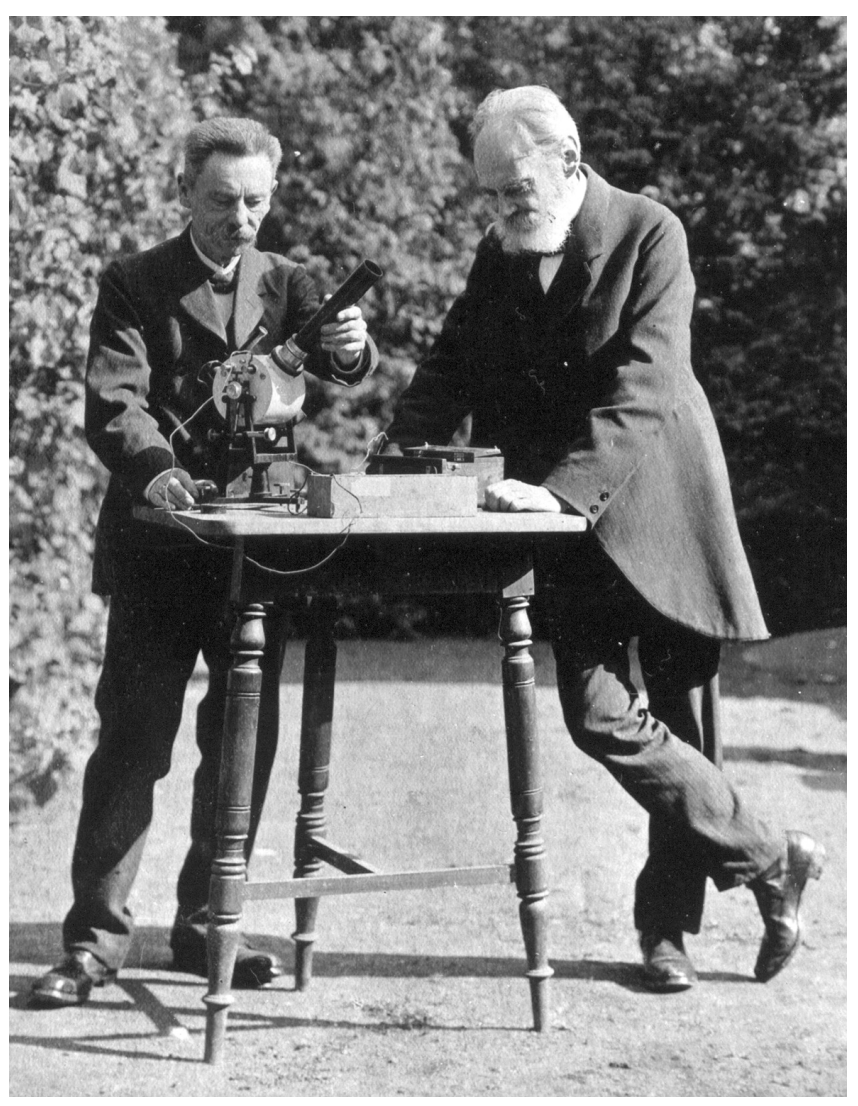

Figure 1. Julius Elster and Hans Geitel experimenting in the garden of Elster's house. The instrument on the table is a photometer (for a description, see Fricke, 1992). Photo: Archiv Fricke.

The knowledge about atmospheric electricity at the end of the 19th century can be summarized as follows: after the experimental proof that lightning is an electric discharge by Thomas-François Dalibard (1709-1788) and Benjamin Franklin (1706-1790) in 1752 important findings were achieved by

Giovanni Beccaria (1716-1781), who established the diurnal variation of the electric state of the atmosphere;

Charles-Auguste Coulomb (1736-1806), who discovered the electrical conductivity of air;

Horace B. de Saussure (1740-1799), who made first quantitative measurements with an electroscope;

William Thomson (1824-1907, ennobled as Lord Kelvin in 1892), who recognized the electric state of the atmosphere as an electric field (potential gradient), established suitable measuring techniques, emphasized the need for continuous quantitative measurements, and established mathematical formulations (Aplin and Harrison, 2013).

It was assumed at that time that Earth carried a negative charge $a b$ origine and that the varying electric state of the 
air was caused by exhalations carrying the negative charge upwards. Almost nothing was known about positive charges and about current flow. The electrical state of the atmosphere was assumed to be a solely electrostatic one. For an overview of the history of the field with extensive references, see Israel (1971) and Aplin et al. (2008).

After publishing their first joint scientific paper about electric phenomena in a flame (Elster and Geitel, 1882), they developed a theory of the electric processes in thunderstorm clouds. This work was based on Elster's $\mathrm{PhD}$ thesis in which he investigated electrical phenomena of finely dispersed liquids (Elster, 1879). Without knowing about electrons and ions they postulated an interaction of charged mist particles and water droplets, leading to a charge separation and a subsequent discharge as lightning. After extensive measurements they published this Influenztheorie, as they named it, and the corresponding results in several papers (Elster and Geitel, 1885a, b, 1887a, b) and presented a summary at the 99th Session of the Kaiserliche Akademie zu Wien (1890). For the necessary measurements of the precipitation electricity they used a device developed themselves using an electroscope (Fig. 2). It should be noted here that Elster and Geitel designed almost all their instruments themselves. Only in the case that they could not build them on their own did they commission professional instrument manufacturers to produce them. The instruments shown and described in Figs. 2 to 4 are typical examples of their ingenuity and experimental skills. Their instruments provided in most cases an improved quality of the measured quantities compared to previous investigation.

In the course of further investigations of the nature of atmospheric electricity they observed a variation of the potential gradient in the atmosphere during a solar eclipse (Elster and Geitel, 1888). Their results confirmed ideas of Arrhenius (1888) that solar UV can give the air an electrical condition. They developed an instrument for quantitative measurements of the intensity of solar radiation, called an "actinometer" (Fig. 3) and were able to establish a quantitative relationship with atmospheric conductivity. They actually used the term elektrische Zerstreuung (electric dissipation). After several improvements their photometer was manufactured by the instrument manufacturer Günther and Tegetmeyer in Braunschweig and was widely used by the atmospheric electricity community. They published their results in an extensive report for the Kaiserliche Akademie der Wissenschaften zu Wien (Elster and Geitel, 1892).

A very important result of their further experiments in photoelectricity was the invention of the photocell for which they obtained a patent (Elster and Geitel, 1893). Since these developments and the corresponding results are beyond the scope of this article, they will not be described here (for details see Fricke, 1992).

A problem with the solar radiation as a source of the electrical state of the atmosphere was that these effects should increase with altitude. The opposite was true however.

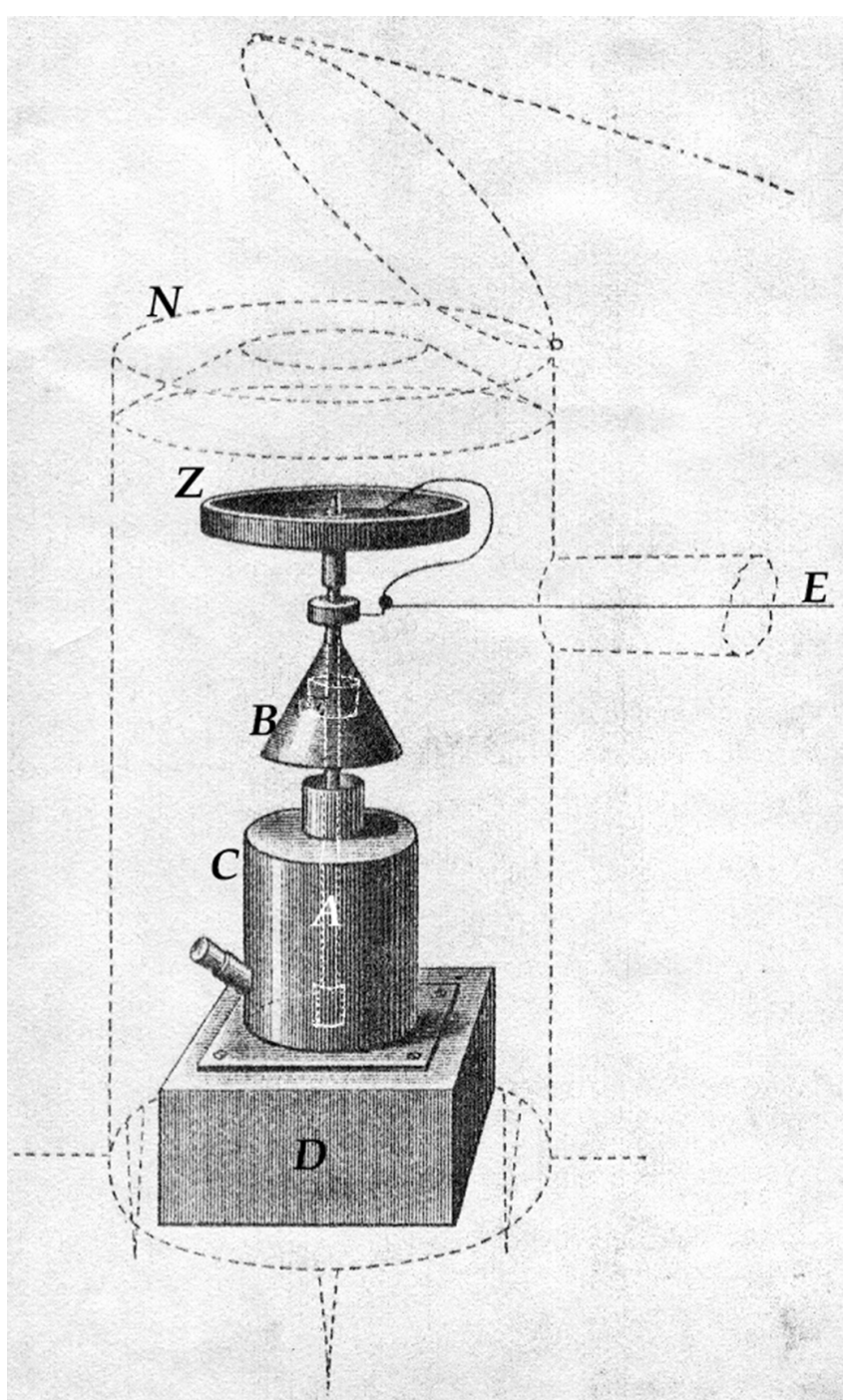

Figure 2. Instrument to measure the charge of precipitation: the rain is collected in an elaborately electrically insulated (A-D) zinc dish $(\mathrm{Z})$ and the electric charge passed to a connected electrometer (E). The arrangement is put into an upward-opening vessel $(\mathrm{N})$ for protection against splashing water and for regulating the incident rain quantity. The whole apparatus was shielded from the atmospheric electric field by a wire mesh (not shown in this figure) (Elster and Geitel, 1890). The development of this device and the corresponding measurements were funded by the American Elizabeth Thomson Science Fund, Boston (Fricke, 1992).

Their extensive experiments at various altitudes up to $3000 \mathrm{~m}$ showed a decrease with height (Elster and Geitel, 1891). These results led the two to a new hypothesis on the nature of atmospheric electricity: the Earth and its atmosphere constitute a spherical capacitor (Elster and Geitel, 1895). The surface of the Earth is negatively charged, the atmosphere positively. The temporal variation of the electric phenomena can then be explained by the exchange and mixing of air at different heights. This was a step towards the concept of the 

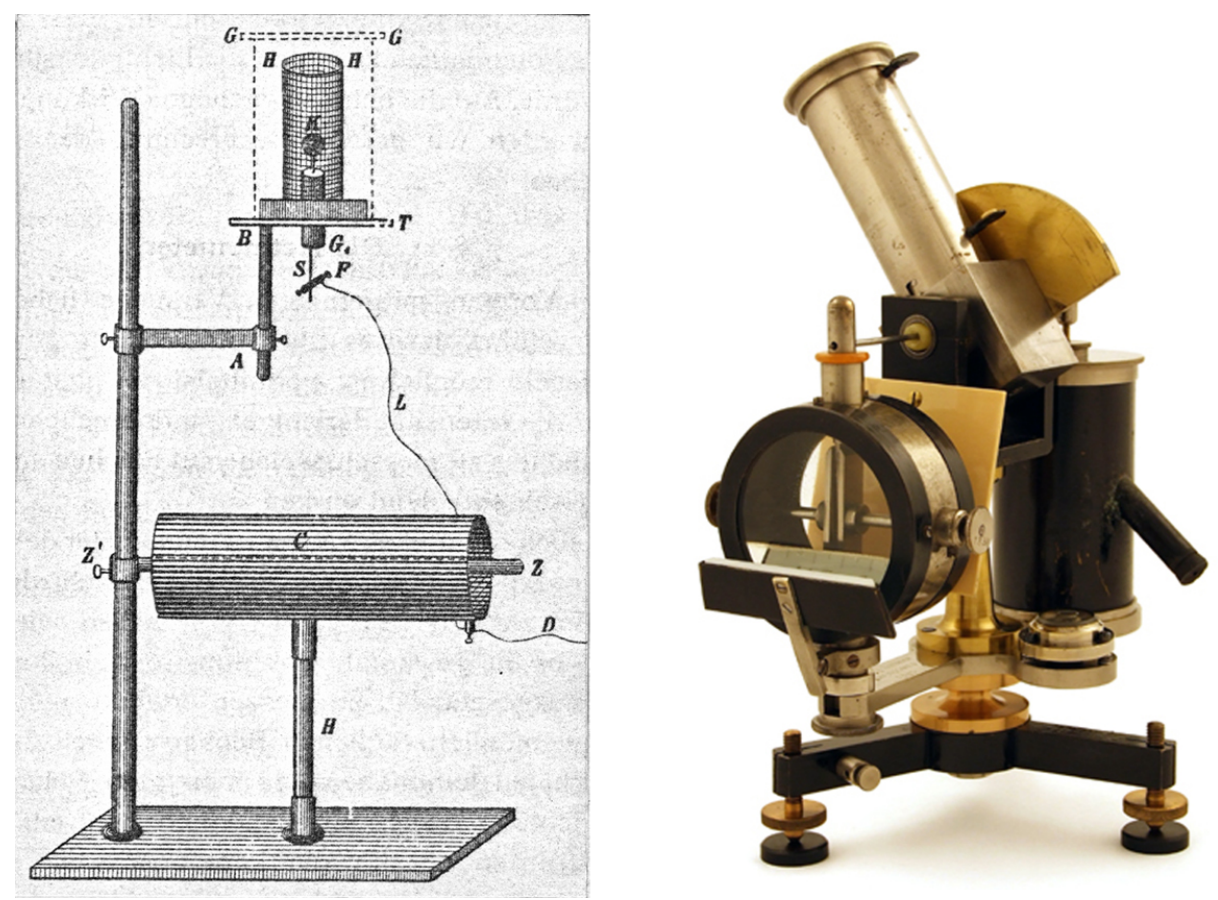

Figure 3. The zinc-sphere photometer (actinometer). Left: design of Elster and Geitel. The light-protected, amalgamated zinc sphere is connected via the capacitor to an electrometer. Before use, the sphere has to be cleaned carefully with a cloth. Then the system is negatively charged, the light incidence is enabled and the charge loss is monitored on the electrometer (Elster and Geitel, 1892). Right: instrument manufactured by Günther and Tegetmeyer (around 1902). Zinc sphere unit and electrometer are combined into a compact instrument (Fricke, 2011).

global electric circuit powered by thunderstorms, discovered after the scientific career of Elster and Geitel (e.g. Wilson, 1921).

Unexplained by this hypothesis remained how the electrical state of the atmosphere took place and what medium carried the charge. In a series of experiments with a device called Zerstreuungsapparat (it actually measured the conductivity of air; see Fig. 4), they investigated the electrical state in detail and came to the conclusion that the air contains small particles of opposite charge. In analogy of the already known ion hypothesis in the electrolysis, they concluded that the positively charged particles are ions (Elster and Geitel, 1899).

This finding led Elster and Geitel to the question of how the ions and negatively charged particles (they did not use the term "electron", although it was already discovered and named by Stoney, 1894) are produced and maintained. Their explanation resulted from a different field of physics: after the discovery of radioactivity by Henri Becquerel (18521908)), (Becquerel 1896), the two became interested in this field and started experiments accordingly. It was already known that radioactive materials ionize the surrounding air. Elster and Geitel measured the behaviour of air in the presence of a radioactive material contained in a bell jar and noticed a similarity with the electric behaviour of free air. They therefore concluded that the atmosphere contains radioactive elements (Elster and Geitel, 1901). In order to prove this they pulled copper wires through their garden and held the wires at a negative potential of about $1 \mathrm{kV}$. They used a discovery by Rutherford that radioactive particles settle on negatively charged bodies. After exposing the wires for several hours they wiped the wires with a piece of leather and subsequently posed them on a sheet of photographic paper. The darkening of the paper was definitive proof that radioactive particles were attached to the leather pieces (Fig. 5). After several weeks they had enough results to publish their discovery that radioactivity causes the ionization of the air (Geitel, 1901).

But how did the radioactive material get into the air? Experiments with soil samples from different locations finally yielded the result that a radioactive gas emanated from the soil, gets into the air by diffusion and subsequently ionizes the air (Elster and Geitel, 1904). This gas, at that time called "radium emanation", had already been discovered in 1900 by Dorn (1901), and only after 1923 was it named radon (today used as an umbrella term for the isotopes from the decay sequences of radium, thorium and actinium).

This discovery by Elster and Geitel marks what could be considered the pinnacle of their work on atmospheric electricity. In the years after 1904 they published mainly improvements in this field of measuring devices and the results of extended measurements at various locations. They had already pointed out several times that long-term and multi- 


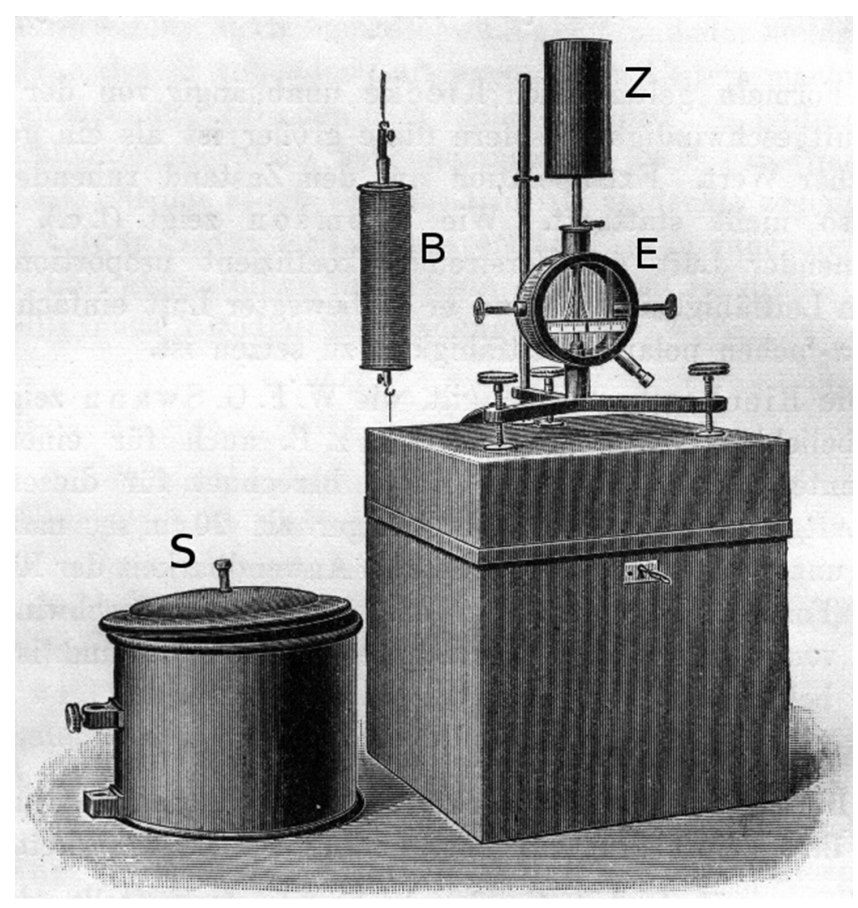

Figure 4. Zerstreuungsapparat (dispersion instrument) of Elster and Geitel: the brass cylinder $(\mathrm{Z})$ was contained in a vessel $(\mathrm{S})$ to shield it from the electric field of the atmosphere. $\mathrm{Z}$ was directly connected to an electroscope (E) in order to measure the temporal decrease of the charge, being proportional to the atmospheric conductivity. B is a dry battery (Zamboni pile) to charge the cylinder (Fricke, 2011).

station experiments are important to understanding atmospheric electricity and established diurnal and annual variations of the corresponding parameters. One of their later experimental campaigns was carried out at Palma on Mallorca from August to September 1905 in order to obtain results before, during and after the solar eclipse of 30 August 1905 (Elster et al., 1906). These investigations were commissioned by the Carnegie Institution of Washington. Elster and Geitel already had contact with this institution for several years. Aware of the scientific cruises (mainly geomagnetic measurements) of the institution's ships Carnegie and Galilee, they wrote a letter to the institution in January 1902 asking to include atmospheric electricity measurements during future cruises as well (Harrison, 2012).

Elster and Geitel published numerous papers on radioactivity. In one of these papers (Elster and Geitel, 1899a) they hypothesized for the very first time that radioactivity may be a consequence of decaying atoms. Their work on radioactivity, however, is not the topic of this article (see Fricke, 1992 for details).

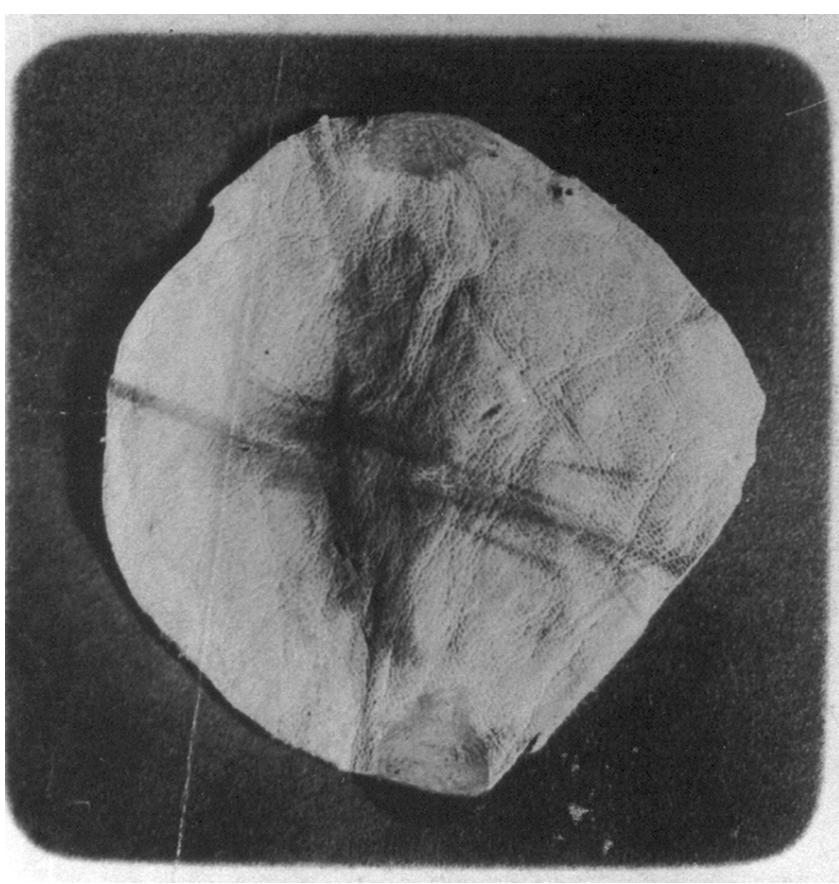

Figure 5. Photograph (blackening due to radioactivity) of a leather piece used to wipe the wires onto which radioactive particles had accumulated.

\section{Recognitions and distinctions}

Elster and Geitel published about 200 papers during their scientific career, 72 of which dealt with atmospheric phenomena. About three-quarters of all their publications named both Elster and Geitel as authors; the rest were published by only one of them (but in these publications they always acknowledged the work of the partner). Although almost all their articles were published in German (two in English, one in French), both were well recognized in the contemporary international scientific community. This proves their extensive scientific correspondence (kept at the Herzog August Library in Wolfenbüttel, Fricke, 1992; Kröger, 1981). They were in contact with practically all important physicists of their time, e.g. Wilhelm Conrad Röntgen (18451923), Henri Becquerel (1852-1908), Heinrich Rudolf Hertz (1857-1894), Wilhelm Wien (1864-1924), Philipp Lenard (1862-1947), Walter Nernst (1864-1941), Otto Hahn (18791968), Max Planck (1858-1947) and Sir William Ramsay (1852-1916). Famous visitors came to Wolfenbüttel for scientific discussions, like Svante Arrhenius (1859-1927), Ernest Rutherford (1871-1973) and Joseph J. Thomson (1846-1940).

Elster and Geitel also travelled to foreign countries to present and discuss their results - for example, in 1896 and 1897 to the Annual Meeting of the Association for the Advancement of Science in Liverpool and in 1904 at the invitation of J. J. Thomson to Cambridge. 
Relatively early in their scientific career Elster and Geitel became honorary members of renowned scientific societies: in 1895 of the Literary and Philosophical Society of Manchester, in 1897 of the Kaiserliche Leopoldino-Karolinische Deutsche Akademie der Naturforscher zu Halle, in 1901 of the Physikalischer Verein Frankfurt, and in 1904 of the Verein für Naturwissenschaften in Braunschweig. In 1901 they both became corresponding members of the British Association of the Advancement of Science. An honorary doctorate of the University of Göttingen was awarded to Geitel in 1899, and to both in 1915 of the Technical University of Braunschweig.

Between 1904 and 1912 Elster and Geitel were nominated seven times for the Nobel Prize in Physics (Crawford, 1987). Unfortunately no details are given about the achievements for which they were nominated. The nominators were Adolf von Baeyer (chemist) in 1904, 1905 and 1909, Hermann Ebert (physicist) in 1906, Adolf von Baeyer and Wilhelm Wien (physicist) in 1907, Adolf von Baeyer, Vincenz Czerny (surgeon), Philipp Lenard (physicist) and Wilhelm Wien in 1910, and Adolf von Baeyer, Vincenz Czerny and Eugen Fischer (chemist) in 1911. These nominators were not really experts in atmospheric electricity; therefore, it is likely that Elster and Geitel were nominated for their work on radioactivity.

Many of the contemporary scientific scholars could not understand that Elster and Geitel did not strive for an academic career at a university. Although both received appeals to the Universities of Berlin and Breslau in 1904, they preferred to stay in their positions at the Gymnasium in Wolfenbuittel and to pursue their private research. (The government in Braunschweig acknowledged their scientific work by reducing their teaching hours.) Only after Elster's death did Geitel accept a position as honorary professor at the Technical University of Braunschweig in 1920, three years before he passed away.

In 1915 Elster's and Geitel's former students Karl Bergwitz (1875-1958), Friedrich Harms (1876-1946) and Hans Witte (1881-1925) (by then physicists as well) prepared a Festschrift to commemorate the 60th birthday of their beloved teachers (edited by Bergwitz, 1915). Comprising 720 pages, it included 60 contributions of important contemporary physicists, astronomers, chemists and mathematicians. It was a very joyful and emotional experience for Elster and Geitel.

\section{Information about the references}

In the following we list only references of Elster and Geitel cited in the text. For a complete list of their publications, see Fricke (1992). We are not aware of any master or PhD thesis ever written about the two scientists, except a diploma thesis on early cosmic ray research in which Elster's and Geitel's work on radioactivity is covered on a few pages (Federmann, 2003).
Acknowledgements. We did not concoct the characterization of Elster and Geitel as Dioscuri (synonym for inseparableness) in the title. To our knowledge it was coined by Max von Laue (1879-1960) in his Geschichte der Physik (von Laue, 1946). Elster's and Geitel's life-long friendship and their joint work, as outlined above (and with more details in Fricke, 1992), seem to justify this denomination.

Edited by: K. Aplin

Reviewed by: two anonymous referees

\section{References}

Aplin, K. L. and Harrison, R. G.: Lord Kelvin's atmospheric electricity measurements, Hist. Geo Space. Sci., 4, 83-95, doi:10.5194/hgss-4-83-2013, 2013.

Aplin, K. L., Harrison, R. G., and Rycroft, M. J.: Investigating Earth's Atmospheric Electricity: a Role Model for Planetary Studies, Space Sci. Rev., 137, 11-27, doi:10.1007/s11214-0089372-x, 2008.

Arrhenius, S.: Über das Leitungsvermögen beleuchteter Luft, Ann. Phys.-Leipzig, 269, 638-643, 1888.

Becquerel, H.: Sur les radiations émises par phosphorescence, C. R. Acad. Sci., 122, 420-421, 1896.

Bergwitz, K. (Ed.): Festschrift Julius Elster und Hans Geitel zum 60. Geburtstag, gewidmet von Freunden und Schülern, Braunschweig, Vieweg, 1915.

Crawford, E. T.: The Nobel population 1901-1937: a census of the nominators and nominees for the prizes in physics and chemistry, Office for History of Science and Technology, University of California, Berkeley, 1987.

Dorn, E.: Über die von radioaktiven Substanzen ausgesandte Emanation, Abhandl. der Naturforschenden Gesellschaft Halle, Band 23, 1-15, 1901.

Elster, J.: Über die in freien Wasserstrahlen auftretenden electromotorischen Kräfte, Inaugural Dissertation, Heidelberg, 1879.

Elster, J. and Geitel, H.: Ueber die Electricität der Flamme, Ann. Physik und Chemie, Neue Folge, 16, 193-222, 1882.

Elster, J. and Geitel, H.: Bemerkungen über den electrischen Vorgang in den Gewitterwolken, Ann. Physik und Chemie, Neue Folge, 25, 116-120, 1885a.

Elster, J. and Geitel, H.: Über die Electricitätsentwicklung bei der Regenbildung, Ann. Physik und Chemie, Neue Folge, 25, 121$131,1885 b$.

Elster, J. and Geitel, H.: Über die Electricitätsentwickelung bei der Tröpfchenreibung, Ann. Physik und Chemie, Neue Folge, 32, 74-91, 1887a.

Elster, J. and Geitel, H.: Zur Frage nach dem Ursprung der Wolkenelektricität, 4. Jahresbericht des Vereins für Naturwissenschaften zu Braunschweig, 40-65, 1887b.

Elster, J. and Geitel, H.: Ueber eine während der totalen Sonnenfinsternis am 19. August 1887 ausgeführte Messung der atmosphärischen Elektricität, Meteorol. Z., 5, 27-28, 1888.

Elster, J. and Geitel, H.: Beobachtungen, betreffend die elektrische Natur der atmosphärischen Niederschläge, 99. Sitzungsbericht der kaiserlichen Akademie der Wissenschaften in Wien, Abtlg. IIa, 421-450, 1890.

Elster, J. and Geitel, H.: Elektrische Beobachtungen auf dem Hohen Sonnblick, Meteorol. Z., 8, 321-333, 1891. 
Elster, J. and Geitel, H.: Beobachtungen des atmosphärischen Potentialgefälles und der ultravioletten Sonnenstrahlung, 101. Sitzungsbericht der kaiserlichen Akademie der Wissenschaften in Wien, Abtlg. IIa, 703-856, 1892.

Elster, J. and Geitel, H.: Verfahren zur Messung von Lichtstärken unter Verwendung einer lichtelectrischen Vacuumzelle - Patentschrift 66969 vom 5. August 1892, Kaiserl. Patentamt Berlin, and Zeitschr. Instrumentenkunde, 13, 474-475, 1893.

Elster, J. and Geitel, H.: Elektrische Beobachtungen auf dem Sonnblick - Nachtrag, 104. Sitzungsbericht der kaiserlichen Akademie der Wissenschaften in Wien, Abtlg. IIa, 37-45, 1895.

Elster, J. and Geitel, H.: Ueber Bequerelstrahlen, 11. Jahresbericht, Verein für Naturwiss., Braunschweig, 271-276, 1899a.

Elster, J. and Geitel, H.: Über die Existenz electrischer Ionen in der Atmosphäre, Terrest. Magnetism, Vol. IV, 213-234, 1899b.

Elster, J. and Geitel, H.: Über eine fernere Analogie in dem elektrischen Verhalten der natürlichen und der durch Becquerelstrahlen abnorm leitend gemachten Luft, Phys. Z., 2, 590-593, 1901.

Elster, J. and Geitel, H.: Über die Radioaktivität der Erdsubstanz als eine der Ursachen des Ionengehaltes der Atmosphäre, Terrest. Magnetism, IX, 2, 49-61, 1904.

Elster, J., Geitel, H., and Harms, F.: Luftelektrische und photometrische Beobachtungen während der totalen Sonnenfinsternis vom 30. August 1905 in Palma Mallorca, Terrestr. Magnetism, XI, 1, 1-44, 1906.
Federmann, G.: Victor Hess und die Entdeckung der Kosmischen Strahlung, Diplomarbeit, Institut für Radiumforschung und Kernphysik, Wien, 2003.

Fricke, R. G. A.: J. Elster \& H. Geitel - Jugendfreunde, Gymnasiallehrer, Wissenschaftler aus Passion, Döring Druck und Verlag, Braunschweig, 1992.

Fricke, R. G. A.: Günther \& Tegetmeyer 1901-1958, Instrumente für die Wissenschaft aus Braunschweig, AF-(Selbst)Verlag, Wolfenbüttel, 2011.

Geitel, H.: Über die durch atmosphärische Luft induzierte Radioaktivität, Phys. Z., 3, 76-79, 1901.

Harrison, R. G.: The Carnegie curve, Surv. Geophys., 34, 209-232, doi:10.1007/s10712-012-9210-2, 2012.

Israel, H.: Atmospheric Electricity, Vol. 1, Israel Program for Scientific Translations, Jerusalem, 1971.

Kröger, B.: Der Nachlass von Julius Elster und Hans Geitel, Klostermann, Frankfurt a. M., 1981.

Stoney, G. J.: Of the "Electron" or Atom of Electricity, Philosophical Magazine, Series 5, 38, 418-420, 1894.

von Laue, M.: Geschichte der Physik, Universitäts-Verlag, Bonn, 1946.

Wilson, C. T. R.: Investigations on Lightning Discharges and on the Electric Field of Thunderstorms, Philos. T. Roy. Soc. A, 221, 73-115, 1921. 